\title{
Reproduction of Remote Sensing Image Using Supervised Mode of Learning Using Artificial Neural Network
}

\author{
Amanjot Kaur, Dr.Kiran Jyoti \\ M. Tech, Computer Science and Engineering,Guru Nanak Dev Engineering College, Ludhiana \\ Assistant Professor, Guru Nanak Dev Engineering College, Ludhiana
}

\begin{abstract}
Remote sensing is the science of gathering information from a location that is distant from the source. Image analysis is the technique of extracting and interpreting meaningful information from a remotely sensed image. The information from an image may be extracted with the help of computer software or be visually considered. Images like such can be acquired in the form of aerial photograph, a multispectral satellite image, Light Detection and Ranging data, a radar data or a thermal image. Remote sensing is a dynamic technical field of endeavor. This paper is based on the technique involved in mapping of Geographic Information System projects.
\end{abstract}

\section{Indexing terms/Keywords}

Light Detection and Ranging (LIDAR); Geographic Information System (GIS); Artificial Neural Network (ANN); Mean Square Error (MSE); Matrix Laboratory (MATLAB); Support Vector Machines (SVM).

\section{Academic Discipline And Sub-Disciplines}

Computer Science and Engineering.

\section{SUBJECT CLASSIFICATION}

Artficial Neural Networks, Remote Sensing and MATLAB.

\section{TYPE (METHOD/APPROACH)}

A novel algorithm has been applied to the digital data using supervised method of learning with the back propagation feed forward neural network. This implementation was done with the help of Matrix laboratory and its tools.

\section{Council for Innovative Research}

Peer Review Research Publishing System

\section{Journal: INTERNATION JOURNAL OF COMPUTERS AND TECHNOLOGY}

Vol. 13, No. 9

editorijctonline@gmail.com

www.ijctonline.com, www.cirworld.com 


\section{INTRODUCTION}

\subsection{Sun Synchronous Orbit}

A Sun-synchronous satellite is any satellite which is placed in a Sun-synchronous orbit. This orbit is one that places a satellite over a given location at the same mean solar time on successive orbits. This is accomplished by tuning the orbital altitude and inclination. The object is to have the same solar illumination angle at each approach with the same orbital motion. The consistency of Sun angle is attained by tuning the inclination to the altitude of the orbit such that the extra mass near the equator causes the orbital plane of the spacecraft to precess with the desired rate: the plane of the orbit is not fixed but rotates slowly about the Earth's axis. Sun-synchronous orbits have inclination angle of about $98^{\circ}$, an altitude of about $600-800 \mathrm{~km}$ and time period of about 96-100 minutes[1].

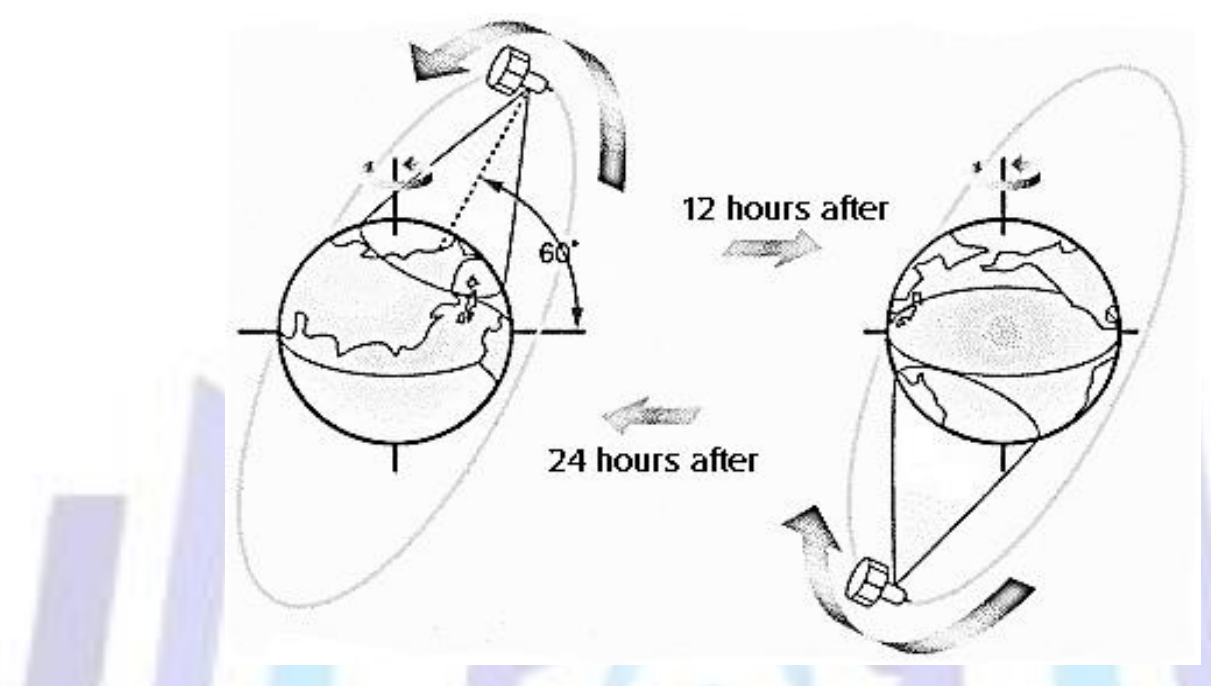

Figure 1: Sun-Synchronous Orbit (Monteverdi, 2013)

Sun-synchronous satellites go around the Earth $24 \times 7$. These acquire the aerial photographs of Earth's field of view and stores the images in a database. These photographs are refreshed during each revolution of the satellite. These images can be retrieved and displayed as and when required.

\subsection{Indian Remote Sensing Satellite}

Indian Remote Sensing satellites (IRS) are a series of Earth Observation satellites, built, launched and maintained by Indian Space Research Organization. The IRS series provides many remote sensing services to India. Data from the IRS satellites is received and disseminated by several countries all over the world. The IRS system is the largest constellation of remote sensing satellites for civilian use in operation today in the world, with 12 operational satellites. It completed its 25 years of successful operations on March $17^{\text {th }}, 2013$ [9]. All these are placed in polar sun-synchronous orbit and provide data/images that have variation of information pertaining to spatial, spectral and temporal resolutions. The National Remote Sensing Centre (NRSC) at Hyderabad is the nodal agency for reception, archival, processing and distribution of remote sensing data in the country. Satellites like Cartosat-1, Cartosat-2 [8], Resourcesat-1, IRS 1D, Oceansat-1 etc acquire and process data for NRSC. 


\subsection{Image Acquisition \& Storage}

Both satellite and surveillance databases are categorically huge and image processing needs to be real time. Satellite imagery is used in the fields of agriculture, forestry, mineral exploration, land-use mapping, weather forecast, mapping of water resources, environmental monitoring and 3D visualization. Real-time imaging with highest possible resolution is required for intelligence and military purposes [9].

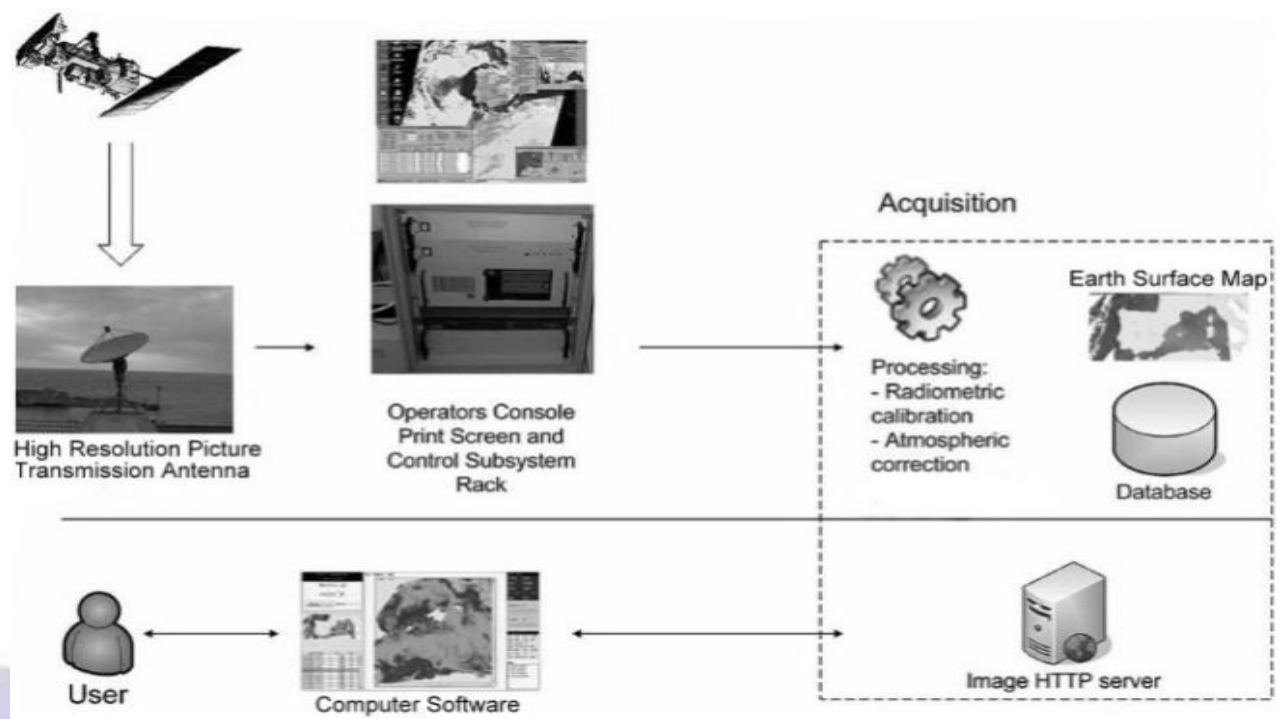

Figure 2: Image Acquisition and Storage (Òscar Chic, 2014)

\subsection{Artificial Neural Networks}

ANN is based on Biological Neuron Model that is a mathematical description of the properties of nerve cells. The artificial neuron is designed to mimic the first order characteristics of the biological neuron [5].

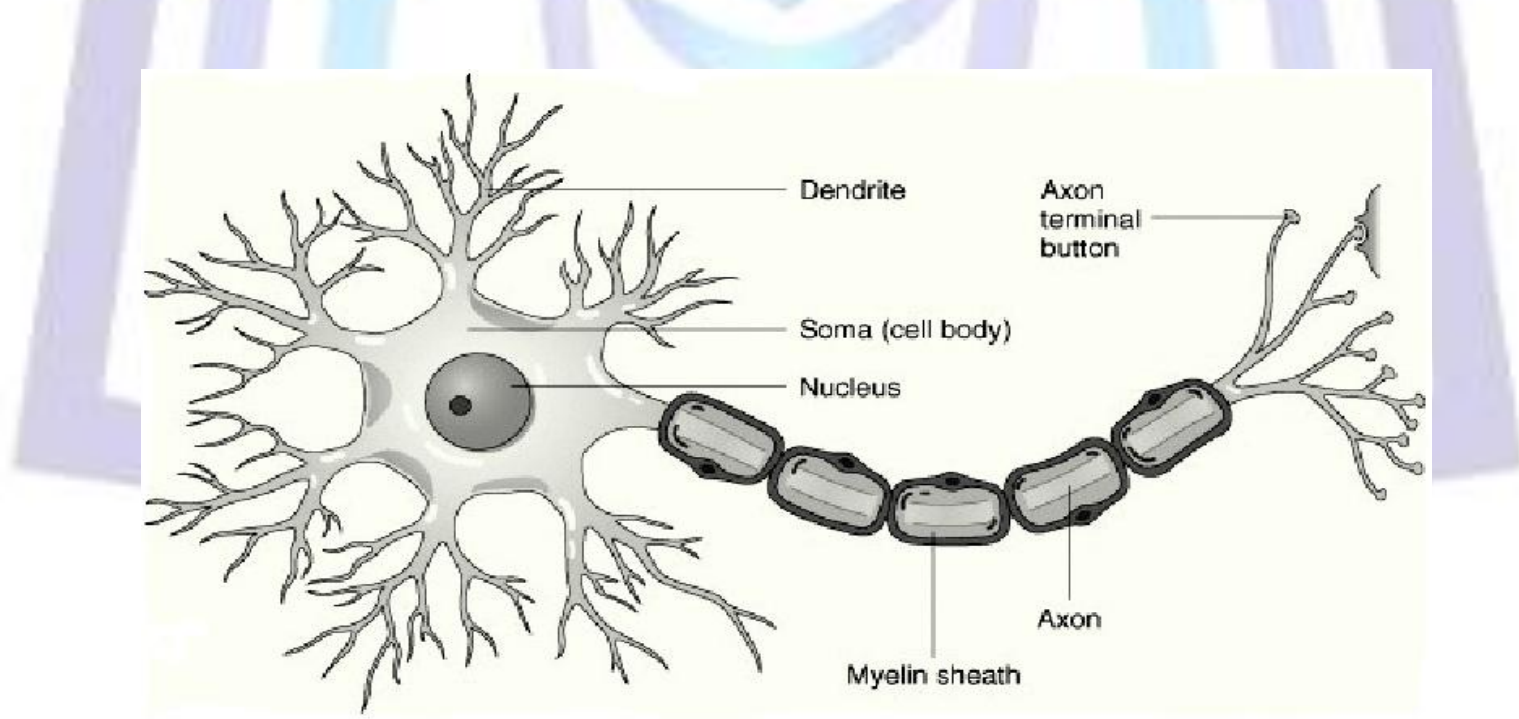

Figure 3: Biological Neuron (Boone, 2014)

When a set of inputs $x$ is applied, then each input is multiplied by corresponding weight w. The weighted input is analogous to a synaptic strength in biological neuron. All the weighted inputs are then summed to determine the activation level of the neuron. Each input signal is multiplied by associated an weight, $w_{1}, w_{2}, \ldots w_{n}$ before it is applied to the summation block, labeled $\sum$. The summation block corresponds roughly to the biological cell body. It adds all the weighted inputs algebraically and produces an output called "NET" [10].

$$
\mathrm{NET}=\mathbf{X W}
$$




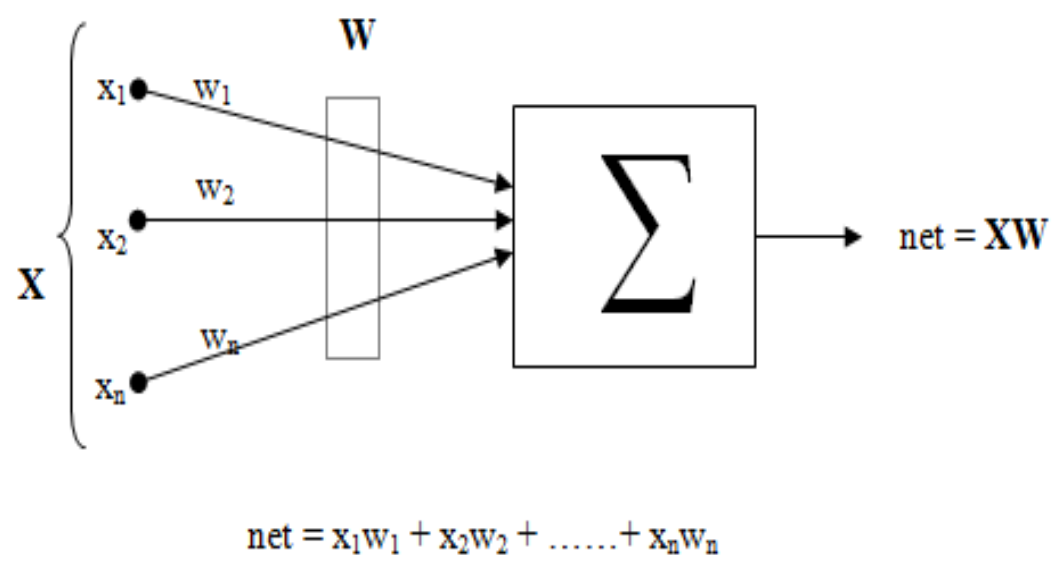

Figure 4: Model of Neuron (Wasserman,1989)

The NET signal is further processed by an activation function F which may be a simple linear function, to produce the neuron's output signal, OUT.

$$
\mathrm{OUT}=\mathrm{K}(\mathrm{NET})
$$

where $\mathrm{K}$ is a threshold function (a constant).

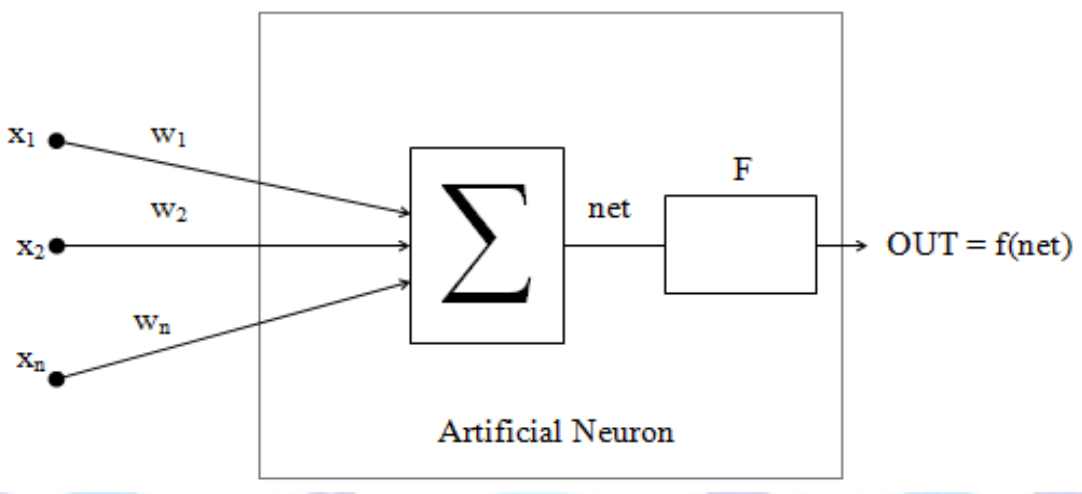

Figure 5: Artificial Neuron with Activation Function (Wasserman,1989)

\subsection{Objective of Training}

An artificial neural network is trained; so that application of a set of inputs vector produces the desired (or at least consistent) set of outputs. Each such input (or output) vector is referred as training pair. Training is accomplished, by sequentially applying input vectors and adjusting network weights according to a preordained subroutine. During training, the network weights gradually converge to the minimal error value. The error back propagation technique is used for training the neural network. When the input vector matched exactly with training pattern the exact output will be produced. In case the input vector does not match exactly with the training pattern, then its approximation matching with the training pattern will give the output using semi supervise mode of learning.

\subsection{Back Propagation}

Backward propagation of error is a commonly used systematic method for training multilayer artificial neural networks [6]. It has great mathematical foundation. Training process using the back-propagation requires the follow steps:

$>$ Select training pair from the training set; apply the input vector to the network input.

$>$ Calculate the output of the network.

$>$ Calculate the error between the output of the network and the required output.

$>$ Adjust the weights of the network such that the error is minimized.

$>$ Repeat the above steps for each vector in the training set until the error for the entire set is admissibly low.

It is a supervised method of learning that is based on Delta rule. According to Delta rule for a neuron $\mathrm{j}$ whose activation function $\mathrm{g}(\mathrm{x})$, j's $i^{\text {th }}$ weight $w_{j i}$ is given as 


$$
\Delta w_{i j}=\alpha\left(t_{j}-y_{j}\right) \mathrm{g}^{\prime}\left(h_{j}\right) x_{i}
$$

\section{Where:}

$\boldsymbol{\alpha}$ is learning rate (constant).

$t_{j}$ is target output.

$h_{j}$ is weighted sum inputs.

$y_{j}$ is actual output.

$x_{i}$ is $i^{\text {th }}$ input.

Delta rule is further simplified as:

$\Delta w_{i j}=\alpha\left(t_{j}-y_{j}\right) x_{i}$

The inputs/weights are applied either from the outside or from the previous layer of the network. These weights must be adjusted such that the error between the desired output and the actual output is reduced. In a way the neural network computes the slightest increase or decrease in the weights.

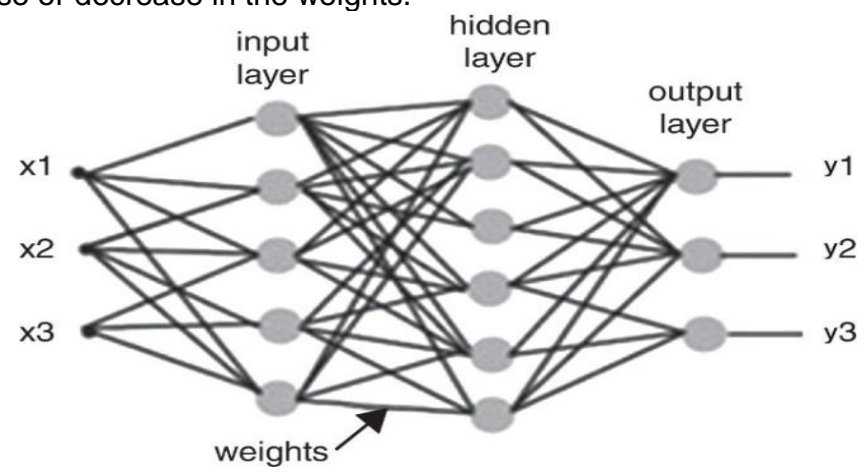

Figure 6: Back propagation Ann (Amirjan,Siadati,2013)

The main aim of the supervised learning algorithm is to find and apply a function that best maps a set of inputs to its accurate output [10].

\subsection{Multilayer Network}

A single neuron can perform certain simple pattern detection functions; the power of neural computation comes from connecting neurons into network. The networks that are large and have certain level of complexity generally offer greater computational skills. The networks have been constructed in every imaginable configuration by arranging the neurons in layers to mimic the layered structure of the certain portion of the brain.

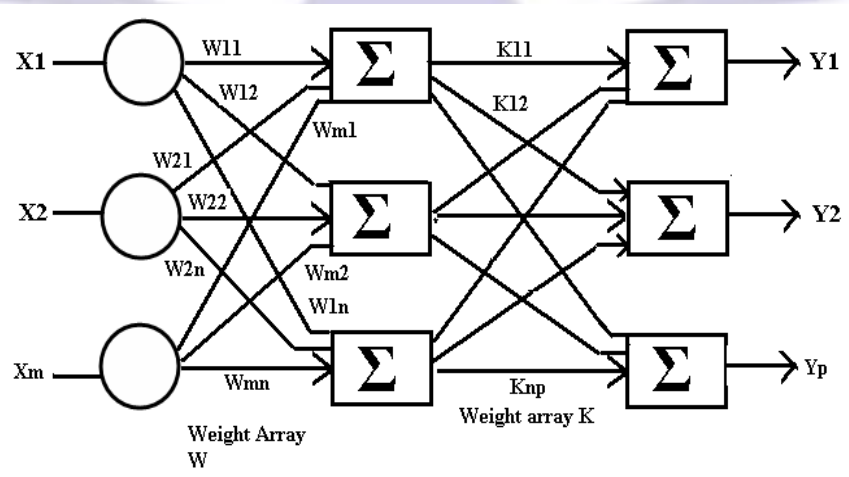

Figure 7: Multilayer network (Wasserman,1989)

The multilayer networks have been proven capabilities beyond those of a single layer, and in recent years, algorithms have been developed to train them. Multilayer networks may be formed by simply cascading a group of single layers; the output of one layer provides the input to the subsequent layer. 


\subsection{Training of ANN}

A set of a digital data pertaining to different landmarks prepared by assigning different area codes according to different topographical features in the form of a binary input of 19 columns is fed to the ANN the target vector is '000001' and similarly for all the target values are a assigned in sequential order and the training pairs are made; which are fed to the ANN one by one [2], [3].

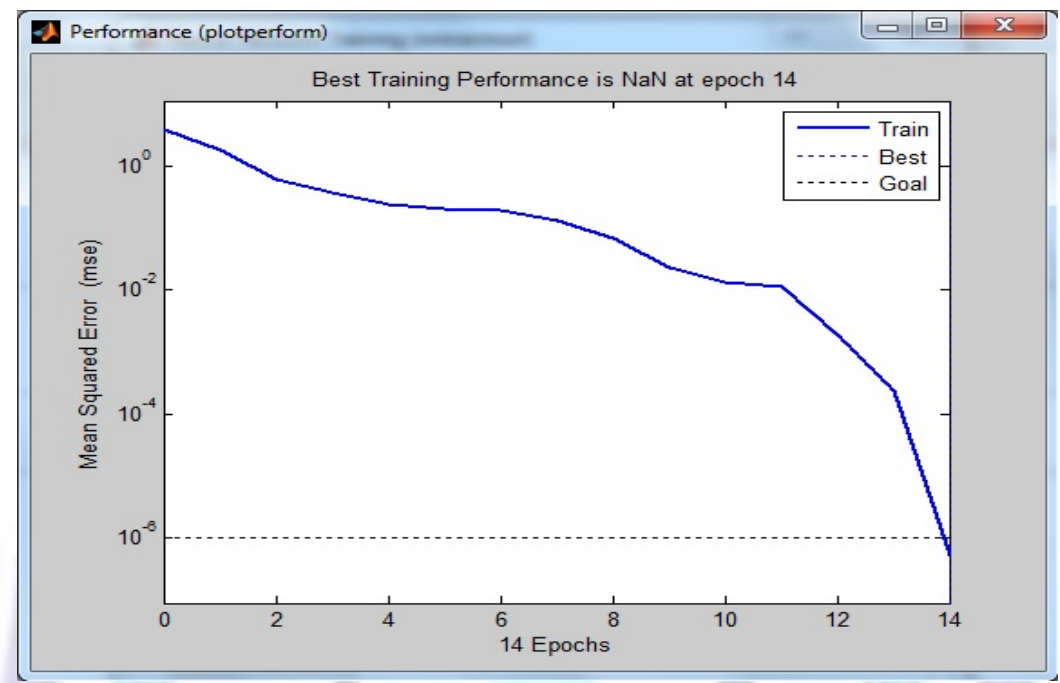

Figure 8: Training Performance

During training of 'EBPANN', each input vector of 19 values; is fed to ANN using MATLAB. These patterns were used to train 19-18-12-6 error back propagation neural network using MATLAB. It was implemented on Intel Core2 Duo processor with $3.0 \mathrm{GHz}$ clock. The neural network was trained for $10^{-6}$ mean square error (MSE). The neural network was trained after 14 epochs in 2 minutes.

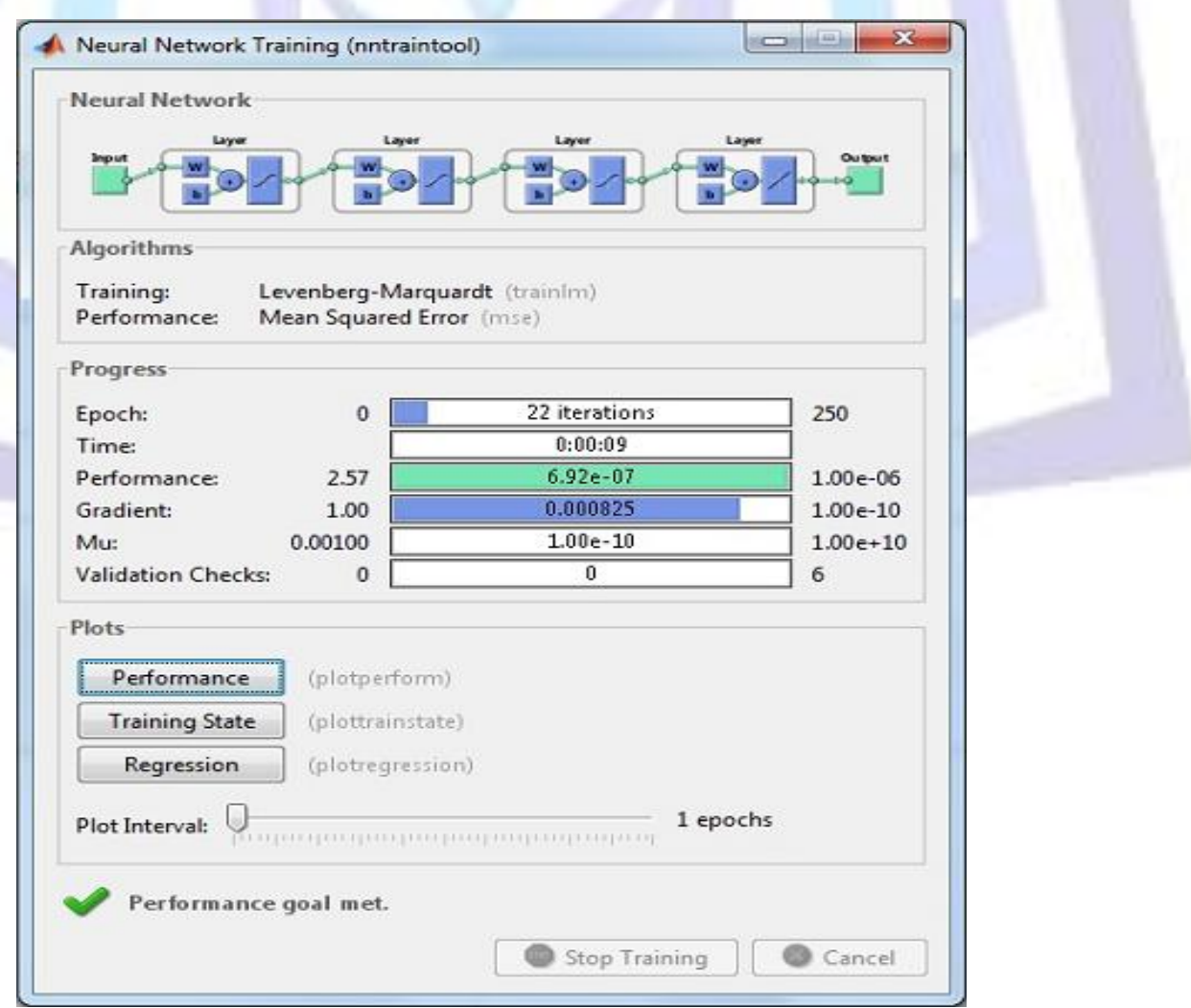

Figure 9: Training of an ANN 
Table 1. Training patterns used for training ANN

\begin{tabular}{|c|c|c|c|c|c|c|c|c|c|c|c|c|}
\hline REGION & AC & $\mathbf{M}$ & $\mathrm{PL}$ & $\mathbf{R}$ & $\mathrm{F}$ & $\mathrm{L}$ & PP & $\mathrm{D}$ & C & MG & I & $\mathrm{O} / \mathrm{p}$ \\
\hline JAMMU \& KASHMIR (u) & 000001 & 0 & 11 & 0 & 11 & 1 & 00 & 0 & 1 & 1 & 1 & 000001 \\
\hline JAMMU \& KASHMIR (I) & 000010 & 0 & 11 & 0 & 00 & 0 & 00 & 1 & 1 & 1 & 1 & 000010 \\
\hline HIMACHAL PRADESH (u) & 000011 & 0 & 11 & 0 & 00 & 1 & 01 & 1 & 1 & 1 & 1 & 000011 \\
\hline HIMACHAL PRADESH (I) & 000100 & 0 & 11 & 0 & 00 & 0 & 01 & 1 & 1 & 1 & 1 & 000100 \\
\hline PUNJAB (u) & 000101 & 1 & 00 & 0 & 01 & 0 & 10 & 1 & 1 & 1 & 1 & 000101 \\
\hline PUNJAB (I) & 000110 & 1 & 00 & 0 & 11 & 0 & 01 & 1 & 1 & 1 & 1 & 000110 \\
\hline UTTRAKHAND (u) & 000111 & 0 & 11 & 0 & 00 & 1 & 00 & 1 & 1 & 1 & 1 & 000111 \\
\hline UTTRAKHAND (I) & 001000 & 0 & 00 & 0 & 00 & 1 & 01 & 1 & 1 & 1 & 1 & 001000 \\
\hline HARYANA (u) & 001001 & 1 & 00 & 1 & 11 & 0 & 01 & 1 & 1 & 1 & 1 & 001001 \\
\hline HARYANA (I) & 001010 & 1 & 00 & 1 & 11 & 0 & 10 & 1 & 1 & 1 & 1 & 001010 \\
\hline RAJASTHAN (u) & 001011 & 1 & 00 & 1 & 11 & 1 & 00 & 0 & 1 & 1 & 1 & 001011 \\
\hline RAJASTHAN (I) & 001100 & 0 & 11 & 0 & 01 & 1 & 01 & 0 & 1 & 1 & 1 & 001100 \\
\hline UTTAR PRADESH (u) & 001101 & 1 & 00 & 0 & 11 & 1 & 10 & 1 & 1 & 1 & 1 & 001101 \\
\hline UTTAR PRADESH (I) & 001110 & 1 & 01 & 0 & 01 & 0 & 10 & 1 & 1 & 1 & 1 & 001110 \\
\hline BIHAR & 001111 & 1 & 00 & 0 & 01 & 1 & 10 & 1 & 1 & 1 & 1 & 001111 \\
\hline JHARKHAND & 010000 & 0 & 01 & 0 & 00 & 1 & 10 & 1 & 1 & 1 & 1 & 010000 \\
\hline SIKKIM+WEST BENGAL (u) & 010001 & 0 & 01 & 0 & 00 & 1 & 00 & 1 & 1 & 1 & 1 & 010001 \\
\hline WEST BENGAL (I) & 010010 & 1 & 00 & 0 & 01 & 1 & 10 & 1 & 0 & 0 & 0 & 010010 \\
\hline NORTH EAST $(u)$ & 010011 & 0 & 00 & 0 & 00 & 1 & 00 & 1 & 1 & 1 & 1 & 010011 \\
\hline NORTH EAST (I) & 010100 & 0 & 01 & 0 & 01 & 1 & 01 & 1 & 1 & 1 & 1 & 010100 \\
\hline CHHATTISGARH (u) & 010101 & 0 & 01 & 0 & 00 & 1 & 01 & 1 & 1 & 1 & 1 & 010101 \\
\hline CHHATTISGARH (I) & 010110 & 1 & 01 & 0 & 00 & 1 & 01 & 1 & 1 & 1 & 1 & 010110 \\
\hline MADHYA PRADESH (u) & 010111 & 1 & 01 & 0 & 01 & 0 & 01 & 1 & 1 & 1 & 1 & 010111 \\
\hline MADHYA PRADESH (I) & 011000 & 0 & 01 & 0 & 00 & 1 & 01 & 1 & 1 & 1 & 1 & 011000 \\
\hline GUJARAT (u) & 011001 & 1 & 10 & 1 & 10 & 1 & 00 & 1 & 0 & 1 & 1 & 011001 \\
\hline GUJARAT (I) & 011010 & 1 & 10 & 0 & 11 & 1 & 10 & 1 & 0 & 1 & 0 & 011010 \\
\hline MAHARASHTRA (u) & 011011 & 0 & 01 & 0 & 11 & 1 & 10 & 1 & 1 & 1 & 0 & 011011 \\
\hline MAHARASHTRA (I) & 011100 & 0 & 10 & 0 & 10 & 1 & 01 & 1 & 0 & 1 & 1 & 011100 \\
\hline ODISHA (u) & 011101 & 1 & 01 & 0 & 00 & 0 & 10 & 1 & 0 & 1 & 1 & 011101 \\
\hline ODISHA (I) & 011110 & 0 & 10 & 0 & 01 & 0 & 01 & 1 & 1 & 1 & 1 & 011110 \\
\hline ANDHRA PRADESH $(\mathrm{u})$ & 011111 & 0 & 01 & 0 & 00 & 0 & 10 & 1 & 1 & 1 & 1 & 011111 \\
\hline ANDHRA PRADESH (I) & 100000 & 1 & 10 & 0 & 10 & 1 & 01 & 1 & 0 & 1 & 1 & 100000 \\
\hline KARNATAKA (u) & 100001 & 0 & 01 & 0 & 00 & 0 & 01 & 1 & 1 & 1 & 1 & 100001 \\
\hline KARNATAKA (I) & 100010 & 1 & 01 & 0 & 01 & 0 & 01 & 1 & 0 & 1 & 1 & 100010 \\
\hline KERALA (u) & 100011 & 1 & 10 & 1 & 00 & 0 & 10 & 1 & 0 & 1 & 1 & 100011 \\
\hline KERALA (I) & 100100 & 1 & 10 & 0 & 00 & 0 & 10 & 1 & 0 & 1 & 1 & 100100 \\
\hline TAMIL NADU $(\mathrm{u})$ & 100101 & 0 & 10 & 0 & 11 & 0 & 10 & 1 & 0 & 1 & 1 & 100101 \\
\hline TAMIL NADU $(\mathrm{u})$ & 100110 & 1 & 10 & 0 & 11 & 1 & 10 & 1 & 0 & 1 & 1 & 100110 \\
\hline LAKSHDWEEP & 100111 & 1 & 11 & 1 & 00 & 1 & 00 & 1 & 0 & 1 & 0 & 100111 \\
\hline ANDAMAN \& NICOBAR & 101000 & 1 & 11 & 1 & 11 & 1 & 00 & 1 & 0 & 1 & 0 & 101000 \\
\hline
\end{tabular}




\begin{tabular}{|l|l|l|l|l|l|l|l|l|l|l|l|l|}
\hline BRIDGE - RAM SETU & 101001 & 1 & 11 & 1 & 10 & 1 & 00 & 1 & 0 & 1 & 0 & 101001 \\
\hline NILE RIVER & 101010 & 0 & 01 & 0 & 10 & 0 & 00 & 0 & 0 & 0 & 1 & 101010 \\
\hline SUNDERBAN DELTA & 101011 & 0 & 00 & 0 & 00 & 0 & 01 & 1 & 0 & 0 & 0 & 101011 \\
\hline HIMALAYAN RANGE & 101100 & 0 & 11 & 0 & 00 & 0 & 00 & 1 & 1 & 1 & 1 & 101100 \\
\hline NORTHERN INDIA & 101101 & 0 & 00 & 0 & 00 & 0 & 01 & 1 & 1 & 1 & 1 & 101101 \\
\hline SOUTHERN INDIA & 101110 & 1 & 10 & 0 & 00 & 0 & 10 & 1 & 0 & 1 & 0 & 101110 \\
\hline EASTERN INDIA & 101111 & 1 & 01 & 0 & 00 & 0 & 01 & 1 & 0 & 0 & 0 & 101111 \\
\hline WESTERN INDIA & 110000 & 0 & 10 & 0 & 01 & 0 & 01 & 0 & 0 & 1 & 0 & 110000 \\
\hline CENTRAL INDIA & 110001 & 1 & 01 & 0 & 01 & 0 & 10 & 1 & 1 & 1 & 1 & 110001 \\
\hline EARTH & 110010 & 0 & 00 & 0 & 00 & 0 & 00 & 0 & 0 & 0 & 0 & 110010 \\
\hline
\end{tabular}

Abbreviation used:
AC-Area Code PP-Population
(u)-Upper (I)-Lower
M-Mountains
D-Desert
L-Lake
PL-Plains
C-Coastal Region
I-Island
R-Rivers MG-Mangrove
F-Forest

\section{CASE STUDIES}

\subsection{Case (1)}

GUJ shows the input concerning to Gujarat landmark topology was given as a test pattern to ANN. The ANN has produced using testing algorithm calculating the output and mapped it accurately with the image of Gujarat.

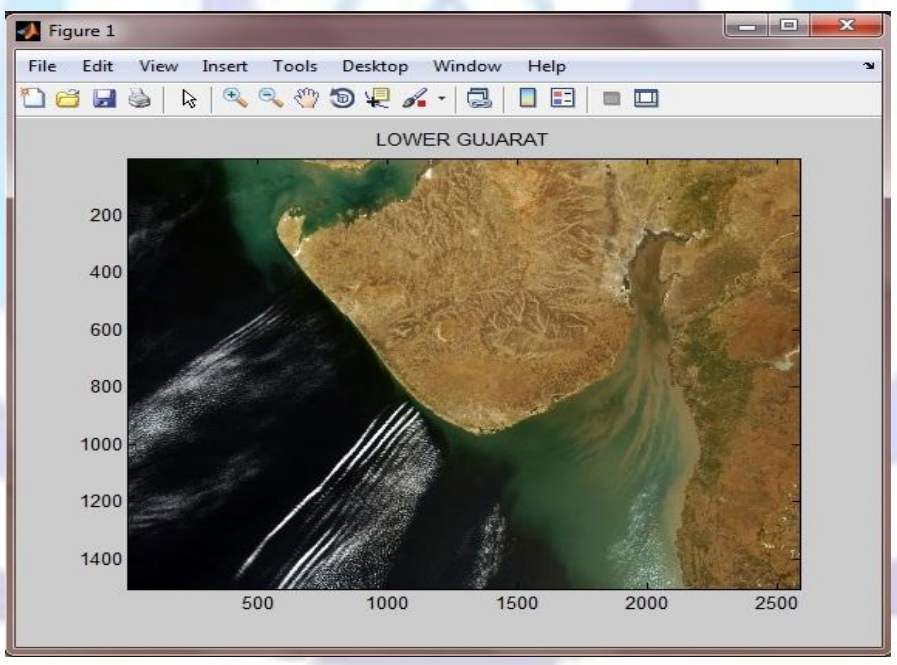

Figure 10: Aerial view of Gujarat

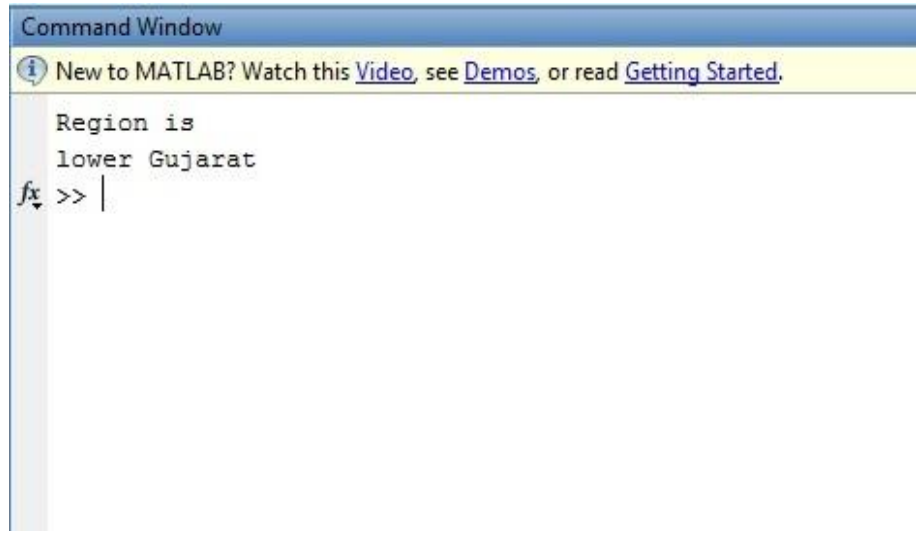

Figure 11: Result given by Algorithm 


\subsection{Case (2)}

BDELTA shows the input concerning to Sunder ban landmark topology was given as a test pattern to ANN. The ANN has produced using testing algorithm calculating the output and mapped it accurately with the image of Sunder bans. The image and the result produced by ANN are exactly matching. Hence it is the case of accurate image reproduction.

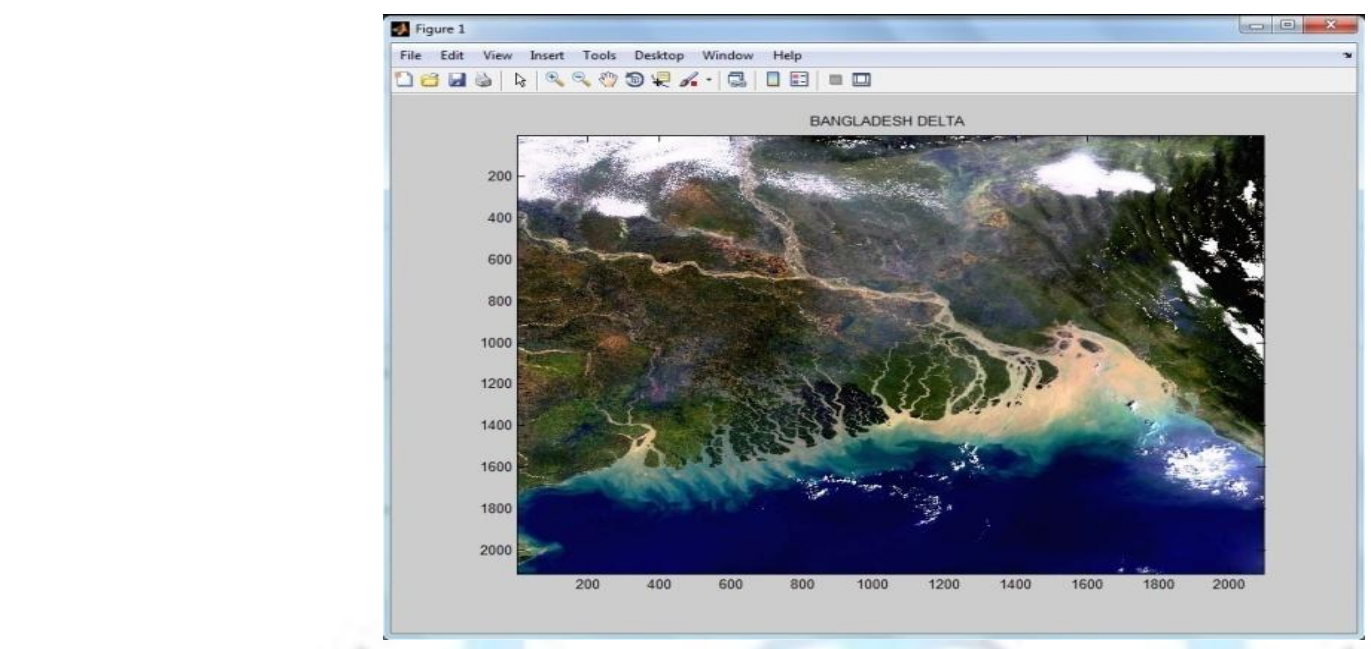

Figure 12: Aerial view of Ganga Delta

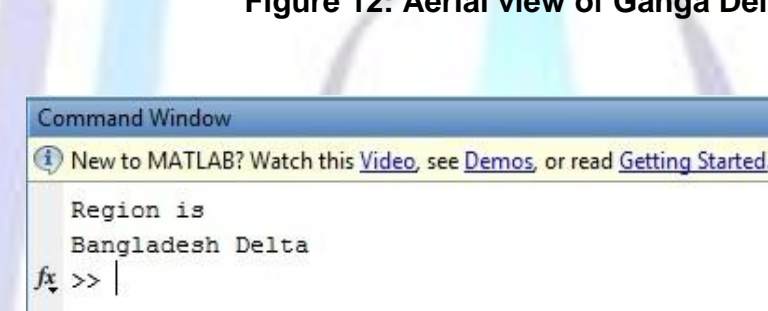

Figure 13: Result given by Algorithm

\subsection{Case (3)}

HIMR shows the input concerning to Himalayan Range landmark topology was given as a test pattern to ANN. The ANN has produced using testing algorithm calculating the output and mapped it accurately with the image of Himalayas.

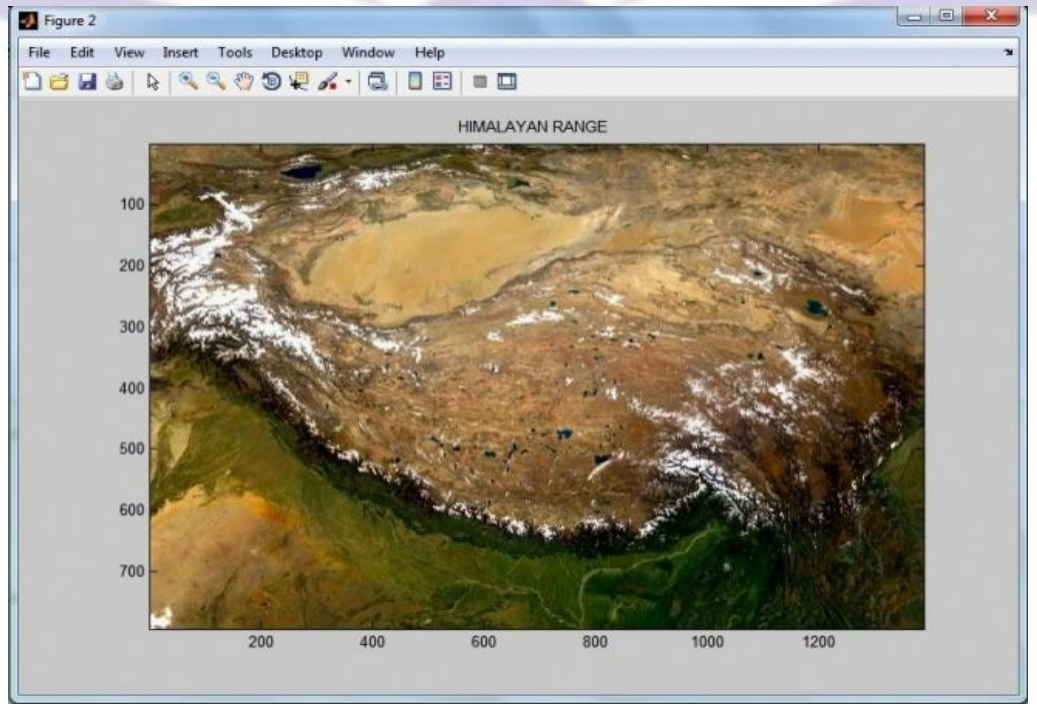


Figure 14: Aerial view of the Himalayas

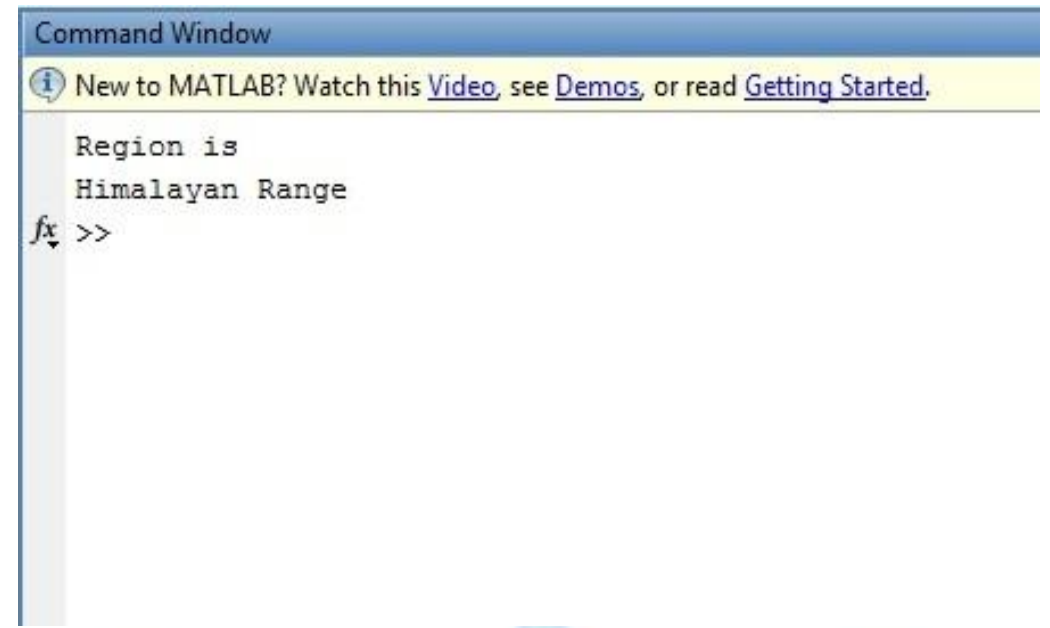

Figure 15: Result shown by algorithm

\section{CONCLUSION}

The technique used for image reproduction using ANN is very accurate method and the results produced are almost $100 \%$. Wavelet and SVMs are equally strong techniques for classification and reproduction of satellite images. The results will be at par with what has been achieved using ANN.

\section{ACKNOWLEDGEMENT}

The authors are highly grateful to the Principal, Guru Nanak Dev Engineering College (GNDEC), Ludhiana, for providing the opportunity to carry out the research work. The constant guidance and encouragement received from Dr.Kiran Jyoti, Assistant Professor Information Technology department, GNDEC Ludhiana has been of greart help. We express our gratitude to Er. D.V. Saini, Asstt. Executive Engineer, PSPCL and Shrija Gairola, M.Tech, Power Engineering, for their intellectual support, guidance and encouragement throughout the course of this work.

\section{REFRENCES}

[1] Boain, Ronald J. February, 2004. A-B-Cs of Sun Synchronous Orbit Mission Design.

[2] Chouhan, V.S. and Mehta, S.S. January-2008. Detection of QRS in 12-lead ECG using Adaptive Quantized Threshold.

[3] Chouhan, V.S., Mehta, S.S. and Lingayat, N.S. April 2008. Delineation of QRS-complex, P and T-wave in 12-lead ECG.

[4] Dadhwal, Vinay K. February-2013. 25 Years of Indian Remote Sensing Satellite (IRS) Series.

[5] LeCun ,Yann, Bottou, Leon, Orr, Genevieve B., Muller, Klaus-Robert. 1998. Efficient Backpropagation.

[6] Melesse, Assefa M., Weng, Qihao, Thenkabail, Prasad S. and Senay, Gabriel B. December-2007. Remote Sensing Sensors and Applications in Environmental Resources Mapping and Modeling.

[7] Maind ,Sonali B., Wankar, Priyanka. January-2014. Research Paper on Basic of Artificial Neural Network.

[8] Radhadevi, P.V., Nagasubramanian, V., Mahapatra, Archana, Solanki, S.S., Sumanth, Krishna and Vardhan Geeta. 2008. Potential of High-Resolution Indian Remote Sensing Satellite Imagery for Large Scale Mapping.

[9] Tuia, Devis,Volpi, Michele, Copa, Loris, Kanevski, Mikhail and Muñoz-Marí, Jordi. June-2011. A Survey of Active Learning Algorithms for Supervised Remote Sensing Image Classification.

[10] Wasserman, Philip D. 1989. Neural Computing : Theory and Practice.

\section{Authors' Biography}

Dr. Kiran Jyoti, born on 9 August 1978 is presently working as assistant professor in IT department at Guru Nanak Dev Engineering College, Ludhiana. She has done Ph.D and has 14 national and international publications and 8 conferences.

Amanjot Kaur, born on 10 August 1987 is presently pursuing M.Tech from Guru Nanak Dev Engineering College, Ludhiana. She has completed her B.Tech from Punjab Technical University. 